\title{
Verifying Nuclear Disarmament
}

\author{
Steve Fetter ${ }^{*}$
}

Commentators differ on whether nuclear disarmament would be desirable, but many argue that disarmament is impractical because it could not be verified. Three reasons are often offered for such pessimism. First, nuclear weapons are small and difficult to detect, and one could not be sure that a few weapons had not been hidden away. Second, nuclear weapons are so destructive that a mere handful would confer enormous military and political advantages over non-nuclear adversaries. Finally, nuclear know-how cannot be eliminated, and any nation that had dismantled its nuclear weapons would be capable of quickly assembling a new arsenal from scratch or using civilian nuclear materials. Because of the difficulty of verifying that other states had eliminated all their weapons and providing adequate warning of their rearming, it is argued, states would not agree to disarm in the first place.

While a degree of skepticism is healthy, recent experiences with nuclear programs in South Africa, Iraq, and North Korea give some hope that disarmament could be verified adequately, partiularly in the sort of international environment in which disarmament was under serious consideration. This paper examines the techniques that could be used to verify that nuclear arsenals had been dismantled and to provide timely warning of any attempt to build nuclear weapons. Although no verification regime could provide absolute assurance that former nuclear-weapon states had not hidden a small number of nuclear weapons or enough nuclear material to build a small stockpile, verification could be good enough to reduce remaining uncertainties to a level that might be tolerable in a more transparent and trusting international environment. And although the possibility of rapid break-out will be ever present in modern industrial society, verification could provide the steady reassurance that would be necessary to dissipate residual fears of cheating. Verification will never be so effective that it can substitute for good relations between nations, but it can play an essential role in consolidating the trust that is necessary to support the ongoing process of reducing nuclear arsenals, perhaps all the way down to zero.

\footnotetext{
Steve Fetter is an associate professor in the School of Public Affairs, University of Maryland, College Park.

This report was produced for the Henry L. Stimson Center's Project on Eliminating Weapons of Mass Destruction.
} 


\section{$\underline{\text { Standards for Verification }}$}

For an agreement to be verifiable, parties must be able to detect militarily significant violations in time to respond and deny the other side the benefit of the violation. What would constitute adequate verification of a nuclear disarmament agreement? How confident must we be that all nuclear explosives had been dismantled? How sure must we be that an attempt to build a small nuclear arsenal would be detected? How much warning must we have of such an attempt? What size violation would be considered "militarily significant?"

Unfortunately, it is impossible to answer these questions in general terms. The demands that we would place on the verification regime would depend first and foremost on the general shape of the world order in which disarmament is considered. Nuclear disarmament could be pursued under conditions of unprecedented world peace and tranquillity, or under widespread and intense fear of nuclear weapons triggered by chaos in Russia, accidental or unauthorized use of nuclear weapons, war in Korea, the Middle East, or South Asia, or blackmail by rogue states or terrorist groups that somehow obtain nuclear weapons. Our standards for disarmament and verification are likely to be considerably lower if disarmament is motivated by a general recognition of the irrelevance of nuclear weapons to maintaining peace and security, rather than a belief that their continued existence is maleficent and destabilizing.

The standard of verification also will depend on the set of safeguards that are erected in connection with the disarmament agreement to protect against the possibility of violations. Safeguards might include defenses against nuclear weapons delivered by aircraft, missiles, or covert means; security guarantees that pledge states to aid victims of nuclear attack or to punish nuclear aggressors; international nuclear or conventional forces of sufficient strength to deter or punish the use of nuclear weapons; or preparations to quickly rebuild national nuclear forces should the verification regime detect violations. Some analysts promote the deterrent effect of nations being ready to "go nuclear" in response to a violation of the disarmament agreement; in this view, disarmament might mean not having assembled weapons, but maintaining the capacity to assemble them in a matter of weeks. ${ }^{1}$ Others

\footnotetext{
${ }^{1}$ See Jonathan Schell, The Abolition (New York: Avon, 1984); also Michael J. Mazarr, "Virtual Nuclear Arsenals," Survival, Vol. 37, No. 3 (Autumn 1995), pp. 7-26.
} 
recommend a ban on nuclear activities of all kinds—civilian as well as military- to build the biggest possible firebreak to rearmament. ${ }^{2}$

It is possible to imagine situations in which the standard of verification might be relatively low. If the collective political will and military ability to punish violators is strong, or if states believed that any advantage that could be obtained by violating the agreement would be short-lived, then incentives to defect from the regime would be small. Unfortunately, it is easier to imagine situations in which would call for a much higher standard: the existence of technically capable aggressive states; the lack of a strong cooperative security regime that incorporates all the major powers; or technical breakthroughs or political breakdowns that made it easier for states or subnational groups to acquire weapon materials clandestinely.

The political and technical circumstances in which nuclear disarmament would be considered seriously by the nuclear-weapon states cannot be predicted with any accuracy. We cannot say whether one weapon or one hundred weapons would be a "significant" violation, or whether one day or one year would represent "timely" warning of such a violation. What we can do is investigate the range of possible verification techniques, intelligence capabilities, and inspection privileges and infer from this what sort of verification standard might be achievable. Having determined what standard of verification is possible, we can discuss the sort of international political environment and types of safeguards that would be necessary to make this standard adequate for disarmament.

\section{Dismantling Nuclear Arsenals}

The first job of the verification regime would be to certify, with a reasonably high level of confidence, that the nuclear arsenals of all nations had been eliminated. For verification purposes, nuclear arsenals can be considered to have three types of components: delivery vehicles and their launchers, nuclear warheads, and fissile materials. Each of these components has an associated complex of production and support facilities that also must come under control. The goal of verification is to ensure that these items, materials, and facilities have been dismantled, destroyed, or converted to peaceful or non-nuclear military uses under appropriate international monitoring.

\footnotetext{
${ }^{2}$ Theodore B. Taylor, “A Ban on Nuclear Technologies,” Technology Review, Vol. 98, No. 6 (August/September 1995), p. 76.
} 
The verification process would begin with a declaration by each state possessing nuclear weapons of the location and characteristics of the weapons and related facilities, followed by a series of "baseline" inspections to verify the accuracy of the declaration. Once an agreed inventory of nuclear weapons and related facilities and materials was established, each item would be dismantled or converted to peaceful use according to specified procedures under international monitoring. The declaration would be updated periodically to reflect these changes. Continuing inspections would be necessary to verify that certain facilities had not been recommissioned or diverted to military use. During the reduction process, and for a very long time thereafter, surprise or "challenge" inspections would be conducted to search for evidence of hidden weapons or facilities that might have been omitted from the declaration.

The following sections describe how the process of declarations and inspections would be applied to delivery vehicles, warheads, and fissile materials. This is followed by an analysis of the only example of voluntary and verified nuclear disarmament - the case of South Africa. I then draw general conclusions about the degree of confidence that states would be likely to have that nuclear arsenals had been eliminated completely.

Delivery vehicles. To date, nuclear arms control has focused on restricting the number of delivery vehicles-particularly ballistic missiles and long-range aircraft. The reasons for this are simple: delivery vehicles and their launchers are easy to count using spy satellites; they usually are the most expensive components of a nuclear arsenal; and the strategic capability of a nuclear arsenal is determined mostly by the number of nuclear weapons that are mounted on long-range delivery vehicles. Delivery vehicles thus have been the chief currency of nuclear capability, and their elimination would be a natural focus of disarmament efforts.

Recent U.S.-Russian arms control agreements provide a useful model for verifying the elimination of nuclear delivery vehicles on a multilateral basis. The Intermediate Nuclear Forces (INF) and START treaties are particularly instructive in three respects. First, these treaties established comprehensive and on-going exchanges of data on the number, location, and technical characteristics of all longrange US and Soviet (now Russian) nuclear delivery vehicles, as well as facilities for their production, testing, storage, maintenance, repair, and training. The accuracy of this data is confirmed by initial and continuing inspections of the declared facilities. Second, these treaties established procedures by which delivery vehicles and launchers can be verifiably eliminated or converted to a non-nuclear 
mission. The elimination or conversion is verified by a combination of national technical means and on-site inspections, depending on the type of delivery vehicle. Third, the treaties provide for "suspect-site" inspections to verify that equipment or activity limited by the treaty is not present at other, undeclared facilities.

In most respects, the INF and START treaties provide a complete set of tools to verify the elimination or conversion of nuclear delivery vehicles and associated launchers and facilities. To make use of these tools in a disarmament agreement, it only would be necessary to apply them in a more comprehensive manner. For example, the START treaties specify procedures for verifiably eliminating certain types of strategic delivery vehicles and launchers: silos for intercontinental ballistic missiles (ICBMs), "heavy" ICBMs, mobile ICBMs and launchers, launch tubes for submarine-launched ballistic missiles (SLBMs), and heavy bombers. The START treaties do not require the elimination of SLBMs, non-heavy silo-based ICBMs, and air-launched cruise missiles (ALCMs), however. Moreover, aside from the INF Treaty's requirement that all ground-launched ballistic and cruise missiles with ranges between 500 and 5,500 kilometers be verifiably eliminated, there is no requirement to limit or eliminate other non-strategic delivery systems, such as tactical aircraft and sea-launched cruise missiles (SLCMs).

A disarmament agreement should require the elimination of all nuclear delivery vehicles, regardless of range. In some cases, the conversion to non-nuclear missions or peaceful applications might be permitted under strict guidelines and verification. For example, START allows the conversion of nuclear bombers to conventional roles, provided that the converted bombers are based separately from nuclear bombers and at least 100 kilometers from nuclear-weapon storage sites, that they are modified so that they cannot carry nuclear armaments, and that they have observable differences from nuclear bombers of the same type. ${ }^{3}$ A similar approach

\footnotetext{
3 "To convert a heavy bomber so that it is no longer equipped for nuclear armaments, all weapons bays equipped to carry nuclear armaments shall be modified so as to render them incapable of carrying nuclear armaments. All external attachment joints for nuclear armaments and all external attachment joints for pylons for nuclear armaments shall be removed or modified so as to render them incapable of carrying nuclear armaments." (Article VI, paragraph 11, Protocol on Procedures Governing Conversion or Elimination.) In addition, non-nuclear bombers may not be based at air bases at which nuclear bombers are based. (Article V, paragraph 23, "Treaty Between the United States of America and the Union of Soviet Socialist Republics on the Reduction and Limitation of Strategic Offensive Arms," 31 July 1991.) Differences that make heavy bombers equipped for non-nuclear armaments distinguishable under START from heavy bombers of the same type equipped for nuclear armaments may include: externally observable features of the fuselage, wing, landing gear, refueling devices, machine gun and cannon armament, and other structural differences; features of joints for attaching armaments and external launchers to the airplane; and features of the launchers, internal weapons bays, and joints for attaching weapons to the launcher.
} 
could be used to convert other types of nuclear delivery vehicles, such as tactical aircraft, ALCMs, and SLCMs, to conventional roles. ${ }^{4}$ Small numbers of missiles might be converted for use as space launch vehicles, subject to realistic projections of future demand and on-going monitoring. Although aircraft and missiles could be converted back into nuclear delivery vehicles, allowing the parties to verify that such systems are not equipped for nuclear delivery would be a useful confidencebuilding measure. Ultimately, however, verification would depend more on ensuring that the nuclear warheads for these systems had been eliminated.

An agreement to eliminate nuclear weapons should be accompanied by a global ban on ballistic missiles with ranges greater than 300 kilometers. Unlike manned aircraft and cruise missiles, longer-range ballistic missiles have little or no utility for the delivery of conventional munitions. ${ }^{5}$ Only a handful of countries have deployed conventionally armed ballistic missiles with a range greater than 300 kilometers. Thus, it should not be difficult to obtain widespread support for a ban on ballistic missiles in the context of nuclear disarmament. Although space launch vehicles are capable of being used as ballistic missiles, a variety of confidence-building measures could be adopted to minimize this danger. ${ }^{6}$

Nuclear weapons. US-Russian efforts to control nuclear arsenals have largely ignored their most fearsome components - the nuclear explosives themselves. This is due to the inherent difficulties in verifying limits on nuclear warheads. Nuclear warheads are small; several could fit in an ordinary garage. They are assembled, transported, stored, and dismantled entirely under cover. National intelligence is incapable of counting an adversary's warheads with any accuracy; US estimates of the number of Russian warheads have an uncertainty measured in the thousands. ${ }^{7}$

\footnotetext{
${ }^{4}$ START allows parties to deploy long-range non-nuclear ALCMs, but it does not specify the differences that would make non-nuclear ALCMs distinguishable from nuclear ALCMs, inasmuch as no long-range non-nuclear ALCMs had been deployed by either side. The Treaty does, however, give parties the right to inspect deployed nonnuclear ALCMs to verify that they are not armed with nuclear warheads, and to verify the features which distinguish them from nuclear ALCMs.

${ }^{5}$ For a discussion of the relative effectiveness of ballistic missiles and aircraft, see John R. Harvey, "Regional Ballistic Missiles and Advanced Strike Aircraft: Comparing Military Effectiveness," International Security, Vol. 17, No. 2 (Fall 1992), pp. 41-83; and Steve Fetter, "Ballistic Missiles and Weapons of Mass Destruction: What Is the Threat? What Should be Done?" International Security, Vol. 16, No. 1 (Summer 1991), pp. 5-42.

${ }^{6}$ For example, tests of SLVs in a ballistic trajectory could be prohibited, as could tests involving high-speed reentry vehicles, or reentry vehicles of a size and shape appropriate for the delivery of nuclear weapons. The total number of SLVs in storage or ready for launch could be restricted, as could the number of launch pads. In addition, payloads could be inspected to confirm the absence of nuclear weapons.

${ }^{7}$ In 1992, the CIA estimated that Russia had 30,000 nuclear weapons, "plus or minus 5,000." (See "Testimony of Lawrence Gershwin before the House Defense Appropriations Subcommittee," 6 May 1992.) Subsequent statements by Russian Minister of Atomic Energy Victor Mikhailov that the Russian stockpile peaked at 45,000
} 
Cooperative means of verification have been resisted because of concerns that they would reveal sensitive information about the design of nuclear weapons or the status of nuclear forces.

This attitude has begun to change recently. In September 1994, Presidents Clinton and Yeltsin agreed to exchange data on their countries' nuclear arsenals, and instructed their experts to meet to discuss what information could be provided to the other side. Such an agreement has not yet been reached, and the parties are likely to begin with a modest exchange of information. Preparations for nuclear disarmament, however, would require a comprehensive declaration, including:

- the location, type, status, and serial number of all nuclear explosive devices;

- the location, status, and description of facilities at which nuclear explosives had been designed, tested, assembled, stored, deployed, repaired, and dismantled; and

- the location, status, and description of facilities that produced key nuclear weapon components, such as high-explosive assemblies and neutron generators; and of facilities that produced or fabricated special warhead materials such as plutonium, highly enriched uranium (HEU), and tritium.

Such information would allow parties to verify the current status of nuclear stockpiles and production complexes, as a basis for verifying the dismantling of warheads and the decommissioning of related facilities. To provide confidence that this information was complete, it also would be helpful to have complete information about the history of the stockpiles, including:

- the history of each nuclear explosive device, including the dates of assembly, movement between various declared facilities, and its dismantling, destruction in an explosive test, or accidental loss; and

- the operating records of the warhead-related facilities listed above.

It is important to begin verifying declarations as far in advance of a disarmament agreement as possible. As the number of nuclear weapons falls into the hundreds, states would be more likely to have confidence in a declaration whose accuracy had been verified for years and for tens of thousands of nuclear warheads, than one 
whose verification had begun recently and only after thousands of warheads had been dismantled. Failure to verify the dismantling and consolidation of the huge US and Russian nuclear stockpiles could undermine confidence in declarations made later about much smaller numbers of weapons. There is little pressure for warheadverification measures today because stockpiles are so large as to make existing uncertainties unimportant. But unless the nuclear powers begin now to describe and verify their warhead stockpiles, when the need for verification is not pressing, they will have failed to lay a foundation that is strong enough to bear the weight of a disarmament regime.

Data on the history of stockpiles and the operation of warhead-related facilities cannot be verified directly, but it could be checked for internal consistency and for its consistency with archived intelligence data. If, for example, US satellites had detected the movement of nuclear warheads from a particular Russian facility on a certain date, this could be checked against the records exchanged between the two countries. The fact that countries would not know what information might be available to other parties would act as an incentive to provide complete and accurate data.

As with declarations on delivery vehicles, the current status of nuclear warheads would be verified by regular and short-notice inspections of declared facilities, combined with challenge inspections to verify the absence of warheads at other locations. During regular inspections, for example, inspectors could count the number of warheads in a particular storage bunker and compare this to the number listed in the data exchange.

Unlike verification of missiles or silos, however, warhead verification raises the question of how inspectors could be sure that objects declared to be warheads were authentic. Without such assurances, parties might fear that fake warheads had been substituted for real ones, with the real warheads hidden to avoid dismantling. Simple radiation detectors could confirm the presence of fissile materials, but not necessarily the authenticity of a nuclear device.

One possibility would be to use a combination of radiation and other signatures to "fingerprint" types of nuclear warheads. Either the country being inspected or the inspecting party could select a nuclear warhead of a particular type for fingerprinting. Detectors could then measure the rate at which gamma rays and neutrons were emitted from the device at several locations; size, weight, and heat output also could be measured. A signature with such detail would be extremely difficult to counterfeit, but it might raise concerns that sensitive design information 
was being revealed. To deal with such concerns, the data could be encoded in such a way that the inspection instrument would give only a "yes" or "no" answer when inspecting a particular device. Such a system has, in fact, been developed by the United States.

During such inspections, it also would be necessary to assure that other, undeclared objects do not contain warheads. If the object was not too large, gamma-ray and neutron detectors could confirm the absence of fissile materials. Large objects could contain enough shielding to prevent such detection in a reasonable amount of time, however, in which case the inspected party should be required to use other methods to demonstrate that no warheads were contained within.

Verification of the declaration would be enhanced and simplified if all declared nuclear warheads were equipped with a unique identification number or "tag" that was specified in the declaration. First, tags would simplify verification because the discovery of an untagged warhead would be prima facie evidence of a violation. Second, tags would allow random sampling to be used to verify declarations, thereby decreasing monitoring effort, cost, and intrusiveness. ${ }^{8}$ Third, tags would allow particular warheads to be tracked as they moved among facilities. If combined with "perimeter-portal" monitoring, tags would allow the declaration to be updated continuously, and would foreclose the possibility that untagged warheads could make use of declared facilities. A nation intending to cheat would be forced to develop a parallel, clandestine system to store, maintain, repair, or deploy illegal warheads-thus increasing the cost of cheating and the risk of exposure.

Perimeter-portal systems are conceptually simple. A monitored perimeter-an existing fence equipped with intrusion sensors-would be installed around facilities where nuclear warheads were kept. The perimeter would contain a portal equipped to detect the passage of a warhead into or out of the facility. Thus, nuclear warheads could not enter or be removed from the facility without detection.

\footnotetext{
${ }^{8}$ Without sampling, inspectors would have to count every warhead at a site, and possibly verify the authenticity of each warhead. Sampling could greatly reduce the number of warheads that would be examined. For example, a detailed inspection of only 28 randomly selected warheads would provide 95 percent confidence that at least 90 percent of these warheads were authentic (or that the number of warheads did not exceed the declared number by more than 10 percent). In addition, there would be only a 25 percent chance that a 5 percent violation would escape detection (i.e., 50 of 1000 warheads were phony or undeclared), and a 1 percent chance that a 15 percent violation would go undetected. Even a 1 percent violation would have a 25 percent chance of detection.
} 
The consolidation of warhead stockpiles in the United States and Russia should reduce greatly the cost of installing and operating perimeter-portal systems. One could begin perimeter-portal monitoring with a single storage facility for warheads slated for dismantling. The next logical step would be to install such systems at other storage facilities, dismantling facilities, and finally at facilities where warheads are deployed.

The monitoring of assembly and dismantling facilities deserves special attention. Unlike the elimination or conversion of delivery vehicles and launchers, the dismantling of nuclear warheads cannot be verified directly without revealing sensitive design information. It is, for example, highly unlikely that Russia would allow US inspectors to observe the disassembly of its warheads (at least while substantial stockpiles of nuclear weapons are still permitted).

The most straightforward solution would be to install perimeter-portal systems at dismantling facilities, and to monitor the flow of nuclear warheads into the facilities and the flow of plutonium pits out. ${ }^{9}$ A particular nuclear warhead would be counted as dismantled when the corresponding pit had been placed in monitored storage. If desired, pits could be fingerprinted and associated with particular warhead types. At specified intervals, all the warheads within the facility could be dismantled and interior inspections allowed to verify that a stockpile of warheads or warhead materials had not been accumulated within the dismantling facility.

A possible complication is the fact that warhead remanufacturing and maintenance activities will take place even at very low levels of nuclear weapons, often in the same facility as dismantling activities. To illustrate how this might be handled, assume that the facility had a single portal through which all materials must enter or exit. Entering the portal would be warheads for dismantling; warheads for maintenance or remanufacture; and new warhead components (pits, tritium bottles, high-explosive assemblies, etc.) for stockpile maintenance activities. Exiting the facility would be reconditioned warheads and components from the dismantled and reconditioned warheads. Inspections at the portal would ensure that objects declared to be warheads or pits of a particular type were authentic, and that no warheads or

\footnotetext{
${ }^{9}$ Such a scheme is described in Theodore B. Taylor and Lev P. Feoktistov, "Verified Elimination of Nuclear Warheads and Disposition of Contained Nuclear Materials," in Francesco Calogero, Marvin L. Goldberger, and Sergei P. Kapitza, Verification: Monitoring Disarmament (Boulder, CO: Westview Press, 1991), pp. 45-66. See also Theodore Taylor, "Technological Problems of Verification," in Joseph Rotblat, Jack Steinberger, and Bhalchandra Udgaonkar, eds., A Nuclear-weapon-free World: Desirable? Feasible? (Boulder, CO: Westview Press, 1993).
} 
pits entered or exited the facility without being detected and accounted for. There would then be a balance between warheads entering the facility for dismantling and pits of the corresponding type exiting the facility; and between warheads of a particular type (and associated warhead components) entering and exiting the facility for stockpile maintenance activities. Because this balance might not be exact during dismantling or maintenance campaigns, the facility's inventory of warheads and pits would have to be taken at agreed intervals.

Regarding warhead components, various levels of accounting, control, and recycling could be permitted:

- Plutonium pits, which are the most expensive and difficult components to produce, should receive the same degree of accounting and control as the warheads themselves. Pits from dismantled warheads should be stored and ultimately converted for disposal or for peaceful use under international safeguards. So long as nuclear stockpiles were permitted, pits from remanufactured warheads could be recycled for use as new pits. Perimeterportal controls should be placed around facilities for fabricating pits.

- So long as nuclear stockpiles were permitted, tritium from both dismantled and remanufactured warheads would be recovered and recycled; thereafter tritium would be used only for peaceful purposes under international safeguards.

- The manufacture of other important warhead components, such as highexplosive implosion assemblies, neutron generators, and fusing and firing systems should be reported, and perhaps subject to inspection.

In all of these procedures, nuclear-weapon states would have to balance the desire for effective verification with the need to prevent the dissemination of sensitive nuclear-weapon design information. Initially, this balance might be served best by having the United States and Russia inspect each other. As the number of nuclear weapons drops, the other three nuclear-weapon states could be invited to join the process on a more-or-less equal basis. At some point, verification would be the responsibility of the IAEA or some other international agency, perhaps using nationals from the nuclear-weapon states for more-sensitive tasks. 
Fissile materials. Fissile materials — highly enriched uranium and plutonium-are the essential ingredients of all nuclear weapons. ${ }^{10}$ They are also the most expensive ingredient. ${ }^{11}$ Control and accounting for these materials therefore must be a fundamental element of any comprehensive disarmament regime, just as it is the basis for the current nonproliferation regime.

As with delivery vehicles and warheads, the first step would be a declaration of existing stockpiles of all fissile materials. In this case, parties would declare:

- the mass, chemical and isotopic composition, status, and location of all fissile materials;

- a description of all facilities that had been used to produce these materials;

- the production records and a material balance for each facility;

- an account of fissile materials otherwise acquired (e.g., from other countries); and

- an account of all fissile materials removed from the inventory (e.g., consumed in weapon tests or nuclear reactors, dispersed in accidents, lost to waste or radioactive decay, or transferred to other countries).

There are two major differences between this declaration and those previously described. First, record keeping in all countries is far better and more accurate for missiles and warheads than for fissile materials. Second, missiles and warheads are subject to simple item accounting; fissile materials are not. Material accounting is subject to errors of measurement and estimation. Although the mass of a finished piece of plutonium or uranium metal can be measured with high accuracy, the amount of material that remains in inaccessible locations within a facility or that is lost to waste streams often is not (and often cannot be) measured accurately.

It is likely that the nuclear weapon states know, with very little uncertainty, how much plutonium and HEU are in their fabricated weapon components, fresh fuel rods, and various storage forms. More problematic is the plutonium and HEU in

\footnotetext{
${ }^{10}$ Fissile materials are those that can sustain a fast-fission chain reaction, and therefore can be used as the basis for a fission explosive. All nuclear weapons contain fission explosives; no weapons rely on fusion alone. Plutonium and HEU (uranium containing more than 20 percent uranium-235) are the most common fissile materials. Other fissile materials exist but are not known to have been used in nuclear weapons. The controls described in this section would apply to these less-common materials as well.

${ }^{11}$ The production of fissile materials accounted for about 90 percent of the $\$ 25$ billion spent by the United States on the Manhattan Project, when its costs are expressed in 1995 prices. (Kevin O’Neill, "Nuclear Materials Production," Nuclear Weapons Cost Study Project (to be published).)
} 
spent fuel; in metal scraps; in powders lining pipes, glove boxes, and ventilation ducts; and in various liquid solutions and wastes. A recent accounting of US plutonium stockpiles revealed that, of the 111.4 metric tons of plutonium produced or otherwise acquired by the United States, nearly 3.4 tons is estimated to have been lost to waste. ${ }^{12}$ Such estimates, however, are subject to large uncertainties, as is illustrated by the fact that the total amount of plutonium actually in wastes is estimated at 3.9 tons.

Estimates of national inventories may contain uncertainties of a few percent. For example, the estimate of the total amount of plutonium produced or otherwise acquired by the United States is 2.8 tons higher than the measured amount of plutonium in current stockpiles ( 99.5 tons) plus the estimated amount removed from the inventory in tests, wastes, reactors, decay, accidents, and transfers (9.1 tons). ${ }^{13}$ This 2.8 tons is the sum of inventory differences at a dozen facilities over fifty years. There is no evidence that any of this plutonium was lost or stolen. Most, if not all, of the inventory difference is the result of errors in measurement and record-keeping, overestimates of the amount produced in reactors, and underestimates of the amount in wastes. In the latter case, a significant fraction of the "missing" plutonium may be recovered as facilities are decommissioned and decontaminated.

Inventory differences are likely to be even larger for US production of HEU, because the United States did not measure how much HEU went into waste streams and did not keep precise records of the enrichment of various product streams. In addition, Russian and Chinese production records probably are considerably less dependable than those of the United States. Although concerted efforts could be made to minimize inventory differences, it seems unlikely that they could be reduced below several percent of the total inventory.

The large uncertainties in fissile-material inventories could prove to be the largest obstacle to verifying nuclear disarmament. As table 1 indicates, the amount of fissile material reserved for military use in the nuclear-weapon states is huge. An uncertainty of five percent in the US or Russian stockpiles corresponds to enough material to build about 5,000 nuclear explosives; in the case of the United Kingdom, France, or China, about 100 nuclear explosives; in the case of Israel or India, about five explosives. To this challenge we also must add the difficulty of accounting for

\footnotetext{
12 "Plutonium: The First 50 Years" (Washington, DC: US Department of Energy, February 1996). One metric ton is equal to 1000 kilograms or 2200 pounds.

13 Ibid.
} 
hundreds of tons of civilian fissile materials (mostly plutonium) in these states that have not been safeguarded by the IAEA. ${ }^{14}$

\begin{abstract}
Table 1. Estimated amount of military fissile material in the nuclearweapon and threshold states, and the corresponding number of nuclear explosives that could be built with this material.
\end{abstract}

\begin{tabular}{lccc}
\hline Country & $\begin{array}{c}\text { Plutonium } \\
\text { (tons) }\end{array}$ & $\begin{array}{c}\text { HEU } \\
\text { (tons) }\end{array}$ & $\begin{array}{c}\text { number of } \\
\text { explosives }\end{array}$ \\
\hline Russia & 120 & 1000 & 100,000 \\
United States & 100 & 700 & 90,000 \\
France & 6 & 15 & 3,000 \\
China & 3 & 15 & 2,000 \\
United Kingdom & 2.6 & 13 & 2,000 \\
Israel & 0.4 & --- & 100 \\
India & 0.4 & --- & 100 \\
Pakistan & --- & 0.2 & 20 \\
\hline Total & 230 & 1700 & 200,000 \\
\hline
\end{tabular}

Source: Frans Berkout, Oleg Bukharin, Harold Feiveson, and Marvin Miller, "A Cutoff in the Production of Fissile Material," International Security, Vol. 19, No. 3 (Winter 1994/95), p. 174. *Assumes 4 kilograms of plutonium or 12 kilograms of uranium-235 for each fission explosive.

\footnotetext{
${ }^{14}$ By 2000 , the nuclear-weapon and threshold states will have produced about 750 tons of plutonium in civilian reactors. Of this, about 180 tons will be separated; the remainder will be contained in spent fuel. Although most of this material will be available to the IAEA under the voluntary safeguards agreements between the nuclear-weapon states and the IAEA, very little will actually be under IAEA safeguards. Albright, et al, World Inventory of

Plutonium and HEU 1992, pp. 109-111.

The plutonium discharged from civilian power reactors contains a higher fraction of certain undesirable isotopes (plutonium-240 and plutonium-241) than does the "weapon-grade" plutonium produced in dedicated military production reactors. These undesirable isotopes produce large amounts of neutrons and heat, complicating bomb design and leading some observers to argue that "reactor-grade" plutonium is unsuited for weapons. The nuclearweapon states would, however, be quite capable of building effective weapons using reactor-grade plutonium. Indeed, any state or group that could make a nuclear explosive with weapon-grade plutonium probably could make an almost equally effective device with reactor-grade plutonium. See J. Carson Mark, "Explosive Properties of Reactor-grade Plutonium," Science \& Global Security, Vol. 4, No. 1 (1993), pp. 111-128.
} 
It would be fairly straightforward, if time-consuming, to verify the accuracy of some categories of information provided in a fissile-material data exchange. For example, inspectors could verify that selected storage canisters contained material of the amount and isotopic composition specified in the declaration. In some cases, such as scraps and wastes, verification will be complicated by physical barriers, safety considerations, and measurement uncertainties. Other information, such as the amount and composition of fissile materials in a particular type of warhead, likely would remain unverified. Of course, as disarmament proceeds, weapons will be dismantled and the pits and other components they contain will be converted to forms appropriate for disposal or peaceful use under international safeguards, as will materials recovered during the clean-up and decommissioning of production and fabrication facilities. At the final stage of nuclear disarmament, more precise measurements could be made and compared with the initial declaration. The prospect that such data eventually would be subject to verification would be a powerful incentive to give accurate declarations at earlier stages.

One problem is that this final stage of disarmament might come decades after the delivery vehicles and warheads had been dismantled. The United States, for example, does not have a facility to process plutonium pits. A decision to build such a facility probably will await a final decision on the ultimate disposition of the plutonium. The clean-up of production and fabrication facilities also will take decades to complete. A full accounting of fissile-material stockpiles is therefore likely to lag considerably behind the rest of the disarmament process.

But even if one could measure precisely the amount of material in the various forms enumerated in the declaration, there would remain the more difficult problem of ensuring that there were no undeclared stocks of material. This would be accomplished primarily by confirming declarations about the total amount of material that had been produced, but, as noted above, it is unlikely that it will be possible to confirm such declarations with an uncertainty of less than five or ten percent.

Verifying declarations of HEU production would begin with a material balance for each enrichment facility. Recorded receipts of uranium hexafluoride would be compared with shipments of enriched product and discharges of depleted uranium. In addition to the total amount of uranium, a mass balance would be done for uranium-235, based on recorded isotopic assays of enriched and depleted material. The overall design and enrichment capacity of each plant would be verified though on-site inspections. Records of the total amount of separative work performed by 
the plant would be compared with its design capacity, the amounts and enrichment levels of product and tails, and, in the case of gaseous diffusion plants, records of electricity consumption. As an added check, the total amount of uranium mined or imported could be compared with the amount used as feed for enrichment plants, taking into account other demand for uranium. The production of LEU also could be compared with records of fuel fabrication and reactor fuel loadings. Even if records were complete and accurate, however, uncertainties of at least several percent could be expected in estimates of the amount of HEU produced.

Verifying plutonium production would involve examining records of the fabrication of uranium fuel and target rods for plutonium-production reactors; the design of the fuel and the reactors, typical fuel loadings in the core, and dates of fuel loading and discharge; monthly production of thermal energy; shipments of spent fuel; the design and chemical flowsheet of the reprocessing plants; monthly production of plutonium product; and the volume, isotopic concentrations, and disposition of the various waste streams. If the records were complete and accurate, this information would allow plutonium production to be estimated with an uncertainty of perhaps five percent.

The value of this method of verifying production declarations would depend almost entirely upon the accuracy, completeness, and authenticity of the records that were provided. One could check that operating records were consistent with declarations, and that the records were internally consistent, but this should not be confused with independently verifying their accuracy. Records can be falsified, and even authentic records may be inaccurate or incomplete. For example, operators of Soviet facilities may have manipulated official production records to cope with the pressures of a rigid quota system.

Thus, it is possible that declarations would be treated with suspicion, and that examination of operating records would fail to resolve such doubts. In these cases, it would be helpful to have recourse to physical evidence that could dispel or support such suspicions, and embolden the international community to take appropriate actions if the suspicions proved warranted.

Production facilities are possible sources of such physical evidence. ${ }^{15}$ In plutonium-production reactors, for example, the ratio of isotopes in permanent components of the reactor (e.g., the graphite moderator, steel fuel supports, or

\footnotetext{
${ }^{15}$ Steve Fetter, "Nuclear Archaeology: Verifying Declarations of Fissile-material Production," Science and Global Security, Vol. 3, Nos. 3-4 (1992).
} 
reactor vessel) can provide an estimate of the total thermal energy, and therefore the total amount of plutonium, produced during the reactor's lifetime. Although estimates derived in this way would be uncertain by perhaps ten percent, they would be largely independent of record-keeping by the host country, and therefore would provide an independent check on the declaration. In the case of uranium enrichment facilities, isotopic ratios in depleted uranium stored on site could confirm records of product and tails assays over a particular time period. Even these types of measurements are not foolproof, however: production reactors might be dismantled before measurements could be made, and depleted uranium could be hidden or used for other purposes (e.g., ballast, bullets, or blending stock).

South Africa: A case study in disarmament. South Africa is the only country known to have crossed the nuclear threshold in both directions. Having built six Hiroshima-type nuclear bombs during the 1980s, South Africa decided in the early 1990s to dismantle its weapons and join the nuclear Non-Proliferation Treaty (NPT) as a non-nuclear-weapon state. South Africa's experience in convincing the international community that it had disarmed is therefore particularly instructive about the promise and problems of verifying disarmament.

Beginning in July 1990, South Africa disarmed in secret. Within a year, the nuclear bombs had been dismantled, documents destroyed, production and assembly facilities decommissioned, and HEU weapon components cast into standard shapes for storage and international inspection. ${ }^{16}$ Only in March 1993 did President de Klerk announce that South Africa had built six nuclear bombs. The South African government apparently had concluded that domestic and international confidence in South Africa's non-nuclear status would be enhanced if a complete disclosure of the program was made. The IAEA was given a full history of the nuclear-weapon program, along with a list of the people involved in it. The Agency was granted permission to conduct inspections at any relevant location and to interview former managers and workers about the program. A special team of inspectors was briefed on the design and production of the bombs, and then verified that six bombs-worth of HEU had been placed under safeguards, that other components had been rendered unusable for weapons, and that weapon-related activities had ceased at various facilities.

IAEA inspectors easily verified that the declared weapons and facilities had been dismantled and decommissioned, and that the declared stocks of HEU had

\footnotetext{
${ }^{16}$ David Albright, "South Africa’s Secret Nuclear Weapons," ISIS Report, May 1994.
} 
been placed in safeguarded storage. Verifying that South Africa did not have any undeclared weapons or stocks of HEU was considerably more difficult, however. This is, of course, the central problem in verifying nuclear disarmament.

In this case, the major problem was verifying the accuracy and completeness of South Africa's declaration of the amount of HEU it possessed. South Africa claimed that the Valindaba enrichment plant had produced considerably less HEU than its design capacity would have allowed, primarily, the South Africans stated, because accidents caused plant shutdowns, and because the plant also was used to produce low-enriched uranium for reactor fuel.

In the end, the IAEA concluded that "the amounts of HEU which could have been produced by the pilot enrichment plant are consistent with the amounts declared." 17 This conclusion was based largely on an analysis of the original, handwritten operating records of the plant which were provided to the Agency, and which the IAEA judged to be authentic. Estimates of the amount of enriched uranium produced by the plant based on these operating records and the plant's specifications matched the South African declaration within an acceptable margin of uncertainty. ${ }^{18}$ A materials balance of the plant, however, revealed much greater uncertainties because plant operators kept poor records of the enrichment of the depleted-uranium tails. Although an assay of the 370 tons of tails, which are stored on-site in some 600 cylinders, would have reduced greatly the uncertainty in the material balance, the IAEA decided that the increased confidence provided by such measurements would not justify their considerable expense. ${ }^{19}$

The lessons of the South African experience for verifying nuclear disarmament are both positive and negative. On the positive side, the experience suggests that when a government makes a full and complete disclosure of past nuclear activities; offers international inspectors unfettered access to all relevant facilities, records, materials, and personnel; and cooperates fully with the investigation to resolve any discrepancies that may arise, the international community can gain considerable confidence in a government's claim that it had disarmed. This conclusion should, however, be tempered by the unique situation of South Africa. Unlike other nuclear-

\footnotetext{
${ }^{17}$ Quoted in Albright, "South Africa's Secret Nuclear Weapons."

${ }^{18}$ The acceptable margin was one significant quantity, or 25 kilograms of HEU. See Albright, "South Africa's Secret Nuclear Weapons," and Office of Technology Assessment, Nuclear Safeguards and the International Atomic Energy Agency, OTA-ISS-615 (Washington, DC: U.S. Government Printing Office, June 1995), p. 85. ${ }^{19}$ See Thomas B. Cochran, "Highly Enriched Uranium Production for South African Nuclear Weapons," Science and Global Security, Vol. 4, No. 2 (1994), pp. 161-178; and Darryl Howlett and John Simpson, "Nuclearisation and Denuclearisation in South Africa," Survival, Vol. 35, No. 3 (Autumn 1993), pp. 154-173.
} 
armed countries, South Africa did not fear attack from adversaries armed with nuclear weapons or superior conventional forces. Indeed, the South African government's greatest concern focused on an internal risk: maintaining control over nuclear weapons in the turmoil that might accompany the movement toward majority rule. That the South African government had little incentive to cheat on its pledge of nuclear disarmament was undoubtedly a major factor in building confidence in that pledge. The standard of verification required by the international community might be considerably greater for countries that are viewed as having powerful incentives to cheat, or in cases in which adversaries would have strong reasons to fear the possibility of cheating. This underscores the importance of viewing verification in its political context, and the need for other mechanisms to reduce incentives to cheat.

On the negative side, the South African experience shows the difficulty of verifying declarations of even small inventories of fissile material. As noted by IAEA Director General Hans Blix, "There is inherent difficulty in verifying the completeness of an original inventory in a country in which a substantial nuclear program has been going on for a long time." 20 Although South Africa's nuclear program may have been substantial and sustained by IAEA standards, it was tiny and transient compared to those of the nuclear-weapon states. We can expect that, like South Africa, many nuclear-weapon states have not kept good records of certain parameters that, while valuable for verification, were not relevant for the production of materials and weapons. If the IAEA had difficulty in verifying the production of a few hundred kilograms of HEU in South Africa, how will it cope with stockpiles a thousand times larger? What if original records are not available or cannot be authenticated? What if production facilities have been dismantled, or plant managers are unavailable for interviews? These are difficult questions that will have to be addressed if disarmament is to be considered seriously.

How confident could we be of disarmament? In the end, then, we come back to the fundamental question: "How confident could we be that states had disarmed?"

We could be confident that the nuclear-weapon states had eliminated the ICBMs and SLBMs that now dominate their strategic nuclear forces. Although a stockpile of hidden stockpile of mobile missiles might escape detection, they soon would loose their military utility without the regular test, maintenance, and exercise activities which would, if carried out, greatly increase the risk of exposure. Of more

\footnotetext{
${ }^{20}$ Quoted in Howlett and Simpson, "Nuclearisation and Denuclearisation in South Africa."
} 
concern would be long-range aircraft and cruise missiles. Even if we could verify that all nuclear-armed aircraft had been destroyed, conventional variants would exist and could be converted to deliver nuclear weapons with little or no warning. Of course, even civilian aircraft or ships could be pressed into service to deliver a hidden stockpile of nuclear bombs. Verifying nuclear disarmament therefore must rely on verifying that no hidden stockpiles of nuclear explosives exist.

We could be confident that a declared number of nuclear warheads had been dismantled if dismantling facilities and fabricated weapon components were subject to verification during the reduction process. Unfortunately, the process of dismantling excess warheads is already well underway in the United States and Russia without the benefit of any verification or transparency measures. As long as the pits remain intact, it may yet be possible to gain a high degree of confidence that a certain number of nuclear warheads were dismantled. If, however, the nuclear components are recast or reused, it will be impossible to verify independently the number or type of weapons that have been dismantled. In that case, one would have to rely primarily on records and assurances provided by the inspected party, supplemented by an imperfect accounting of the fissile materials that had been placed under safeguards.

A statement that all warheads had been dismantled would be even more difficult to verify, however, resting largely on the perceived accuracy and authenticity of records provided by the inspected party, the testimony of relevant officials, and political judgments about the disarming party's incentives to cheat. A added degree of confidence would be obtained if all fissile materials had been declared and accounted for. At best, however, the inspection agency would be able to conclude that there was no evidence that materials had been hidden, that the declarations of amounts of material produced and stockpiled were consistent with available records and physical evidence, and that any discrepancies were within the uncertainties inherent in the estimating procedure. Unfortunately, these uncertainties will be very large - at least several percent of the total amount of material produced. A declaration that is verified to the best of our abilities would not prove, therefore, that weapon states had not hidden significant amounts of fissile materials-perhaps enough to make hundreds of warheads-from international inspectors.

From a purely technical point of view, it would not be difficult to hide the existence of a few dozen (or perhaps even a few hundred) nuclear devices-or enough material to build dozens or hundreds of bombs-from inspectors. A nation could falsify records to show that the hidden warheads or materials had never been 
produced. Alternatively, a country could claim that hidden warheads had been lost on sunken submarines or ships, in airplane crashes, or in nuclear tests, or that hidden materials had been lost in wastes. ${ }^{21}$

The infrastructure required to support and maintain a small, secret arsenal need not attract attention or require significant amounts of money. The warheads themselves are small; several bombs or cruise-missile warheads could be transported in a common delivery truck and stored in any warehouse. Only a small cadre of trained personnel would be required to examine the warheads from time to time for signs of deterioration. Some weapons would require a fresh supply of tritium to give their design yield, but the required tritium could be diverted from civilian stocks only if and when the weapons were needed. A hidden stockpile of fissile materials would, by itself, be easier to hide than a stock of warheads. The strategic value of such stocks would depend, however, on a country's ability produce weapons quickly using these materials, and maintaining or creating a capability to do so would be far more difficult to hide from an inspection agency.

It is unlikely that hidden warheads or stocks of fissile materials would be discovered unless someone aware of their existence leaked information about their location. It is precisely because of the inherent weakness of technical means of verification in detecting small violations that some analysts stress the importance of "whistle-blowing" or "societal verification," a subject which is taken up in detail in the next chapter.

In short, one could never be certain that a country that had built a substantial nuclear arsenal had disarmed completely. It is highly unlikely that an international inspectorate would be able to prove beyond a reasonable doubt that the United States or Russia had not sequestered a dozen or so "bombs in the basement" (or enough plutonium to build a dozen bombs), short of administering truth serum or polygraph tests to the nation's highest political and military leaders. But this conclusion, while important, is intuitively obvious. The more important question is whether the theoretical possibility of cheating makes disarmament impossible in practice.

\footnotetext{
${ }^{21}$ The United States and Russia have both lost nuclear-armed submarines at sea, and there would be no way to independently verify the number of weapons on board. Many US nuclear weapons were involved in aircraft crashes, although all of the weapons were recovered. Finally, dozens of US nuclear weapons were used, but probably not destroyed, in weapons-effects tests.
} 
No treaty is perfectly verifiable. Fortunately, perfection is not an appropriate standard. A verification regime only can reduce the likelihood of cheating by making it costly and risky, and by diminishing the magnitude of cheating that could go undetected. It cannot make undetected cheating impossible. Ultimately, states must judge whether the benefits of nuclear disarmament outweigh the risks of possible cheating. The risks of cheating depend far less on the characteristics of the verification regime than on the probability that states that disarm might become hostile, on the perceived value of small numbers of nuclear weapons in securing the goals of such hostile states, and on the precautions states had taken to protect against the possibility of cheating.

\section{Detecting Rearmament}

Besides verifying that all nuclear weapons had been dismantled and that all fissile materials had been placed under international safeguards, the verification regime would have to be able to provide timely warning of any attempt to build new nuclear weapons or to reconstruct dismantled nuclear arsenals. In contrast with verifying disarmament, the international community already has considerable experience with verifying that countries are not building nuclear weapons, at least with respect to the non-nuclear-weapon states that are parties to the NPT. Much of this experience would be directly applicable to monitoring a comprehensive nuclear disarmament regime, although the standards for verification would have to be higher than they are at present, for two reasons. First, the former nuclear-weapon states would have considerable experience in producing nuclear weapons and their components, and presumably would find it much easier to circumvent current safeguards without detection than states that had never produced nuclear weapons. Second, the nuclear-weapon states are likely to require that barriers to the acquisition of nuclear weapons by current non-weapon states be increased as one condition for agreeing to dismantle their own arsenals.

Under the NPT, non-nuclear-weapon states promise "not to manufacture or otherwise acquire nuclear weapons or other nuclear explosive devices." The Treaty acknowledges the right of these states, in forgoing nuclear weapons, to enjoy the peaceful uses of nuclear energy. To prevent the "diversion of nuclear energy from peaceful uses to nuclear weapons," the non-nuclear-weapon states agree to accept IAEA safeguards on all their nuclear activities. In addition, all parties agree not to transfer nuclear materials or equipment to any other state unless those materials or equipment are subject to IAEA safeguards. 
IAEA safeguards are designed to detect diversions of significant quantities of nuclear material with high confidence, and to provide warning of such diversions in a timely manner. ${ }^{22}$ The safeguards are based on audits of each country's internal records of nuclear-material inventories and changes in those inventories at each facility, and on the collection of data to verify the accuracy of those records. IAEA inspectors count items such as fuel rods, estimate amounts of nuclear material, affix seals to indicate whether items have been moved or tampered with, and install video cameras and radiation detectors to monitor the movement of nuclear materials. Inspectors also verify the design of facilities to understand their capacity and the flow of nuclear materials within them, and to evaluate the operator's measurement systems. The frequency of inspections depends on the quantity and quality of nuclear material present. Facilities containing spent reactor fuel, for example, are inspected less frequently than those with separated HEU or plutonium, but more frequently than facilities containing only natural or low-enriched uranium (LEU).

Improving IAEA safeguards. Revelations in the wake of the Persian Gulf War that Iraq had pursued an extensive nuclear-weapon program while a member of the NPT focused international attention on the shortcomings of IAEA safeguards. Among these are the weak authority of the Agency to conduct inspections on short notice and at undeclared facilities, the inability of the IAEA to focus inspection effort on states of proliferation concern, the focus only on nuclear materials to the exclusion of other weapon-development activities, the right of states to refuse certain inspectors or inspectors from certain states, and a shortage of funding to achieve inspection goals. ${ }^{23}$

At a minimum, these defects in IAEA safeguards would have to be corrected before the safeguards could be used as a basis for monitoring a comprehensive disarmament agreement. The single most important factor in the failure of safeguards in Iraq was the inability to detect undeclared facilities. A country could attempt to violate a disarmament agreement either by diverting fissile material from declared facilities or by building secret facilities to produce unsafeguarded material. IAEA inspections are designed to detect the diversion of significant amounts of

\footnotetext{
${ }^{22}$ The IAEA defines "high confidence" as a 90-percent probability of detecting the diversion of a significant quantity of nuclear material. A "significant quantity" is defined as 8 kilograms of plutonium or 25 kilograms of uranium-235 in the form of HEU, which represents the amount thought to be needed for a state to make its first nuclear explosive, taking into account processing losses. "Timely warning" is based on the estimated time it would take for a state to convert the diverted material into a finished weapon component; for unirradiated plutonium or HEU, the IAEA goal is to detect diversions within one month; for irradiated plutonium or HEU (e.g., spent fuel), three months; for natural or low-enriched uranium, one year. See OTA, Nuclear Safeguards, p. 45, 57.

${ }^{23}$ This section draws heavily on chapter 3 of OTA, Nuclear Safeguards.
} 
material from declared facilities, and they have been highly effective in accomplishing this goal. ${ }^{24}$ It is precisely for this reason that countries have been, and would continue to be, more likely to cheat by constructing clandestine nuclear facilities.

If discovered, the mere existence of an undeclared nuclear facility would be prima facie evidence of a violation sufficient to prompt the international community to take action. The challenge is to detect undeclared facilities in the first place. With a reasonably high probability, the verification system must provide clear and convincing evidence of an undeclared facility, if one exists. Just as important, it must provide adequate reassurance when no such facilities exist.

At least four major changes in the current safeguards regime are required to deal with the possibility of undeclared facilities. First, high-quality intelligence information, particularly high-resolution imagery and signals intelligence that might reveal the construction and operation of clandestine nuclear facilities, must be incorporated in the verification process. Today, this information is available only through national intelligence. The quality of commercial imagery will continue to improve in the coming decades, but it is unlikely that any commercial service will approach the overall intelligence capabilities of the United States. Before the Persian Gulf War, governments did not share information about the Iraqi nuclear program, if they had any, with the IAEA. The United States and other countries subsequently have been more forthcoming in sharing intelligence information with the IAEA, and US satellite photographs were vital in mobilizing international support for IAEA efforts to uncover undeclared nuclear activities in Iraq and North Korea.

Such informal, ad-hoc, and one-sided mechanisms are unlikely to be adequate under a general disarmament agreement, however. As long as the best intelligence information is in the hands of a few countries, observers will expect that these countries will use the information for their own purposes. The fact that intelligence assets are concentrated in the hands of the current nuclear-weapon states may be particularly troubling. Although some might hope that these countries would keep an eye on each other, others might fear that they would collude to keep secret the existence of certain facilities. If, on the other hand, high-quality intelligence

\footnotetext{
${ }^{24}$ There have been no known diversions of significant amounts of safeguarded material, and no reason to believe that such diversions have occurred without detection. Iraq and Romania used safeguarded research reactors to produce gram quantities of plutonium. North Korea and Pakistan also may have diverted small amounts of material from safeguarded facilities, but in neither case were full IAEA safeguards in effect.
} 
information became more widely available, it would be more likely that countries that wished to cheat would learn how to hide their nuclear activities.

Second, extensive environmental monitoring would improve substantially the ability to detect undeclared facilities, by detecting the distinctive radioactive or chemical substances emitted during their operation. ${ }^{25}$ Environmental sampling would be especially effective in detecting plutonium separation, since large amounts of radioactive gases are released into the environment when the spent fuel is dissolved. These gases can be trapped with considerable difficulty and expense, but releases cannot be eliminated entirely. Uranium enrichment is much harder to detect because emissions are low and uranium exists in nature; depending on the enrichment process used, enriched uranium might be detected only a few kilometers or less downwind. High concentrations or unusual chemical forms of uranium in the air or water, however, could indicate the presence of undeclared uranium mining, purification, or conversion operations.

The operation of most existing nuclear facilities can be detected rather easily because of their large size, and because precautions usually have not been taken to disguise their emissions. Nuclear reactors, for example, typically are built above ground on the shores of a large body of water, and are easily recognized by their distinctive appearance and the discharge of large quantities of heat. Releases of radioactive gases from existing reprocessing plants can be detected thousands of kilometers downwind, and particles of enriched uranium from commercial enrichment plants can be detected at distances of tens of kilometers. Nuclear facilities sized to produce only a few bombs-worth of material each year, however, would be more difficult to detect, especially if precautions were taken to disguise the facility and to minimize emissions. In those cases, detection would rely primarily on the possibility of accidents.

Third, the chance of detecting clandestine nuclear facilities could be increased by expanding the scope of safeguards to include uranium mining and milling operations. Currently, safeguards begin when uranium is converted into a chemical form suitable for fuel fabrication or uranium enrichment; inventories of refined natural uranium ("yellowcake") are neither reported nor safeguarded. A clandestine effort to produce plutonium or HEU would require substantial quantities of

\footnotetext{
${ }^{25}$ Office of Technology Assessment, Environmental Monitoring for Nuclear Safeguards, OTA-BP-ISS-168 (Washington, DC: U.S. Government Printing Office, 1995).
} 
uranium -5 to 10 tons of yellowcake per significant quantity. ${ }^{26}$ A program to produce enough material for five weapons per year would require 25 to 50 tons of yellowcake per year, which is a detectable mining and milling operation. ${ }^{27}$ Extending safeguards to yellowcake and uranium ore would make it difficult to divert uranium from safeguarded mines and mills to clandestine fuel-fabrication or uranium-enrichment facilities, and it would make undeclared mining and milling vulnerable to detection.

Fourth, the IAEA's authority to inspect undeclared sites on short notice could be improved dramatically. Current safeguards agreements include provisions for "special" inspections at undeclared sites, but these inspections must be carried out "in consultation" with the state. In practice the IAEA must notify the state in advance, provide reasonable justification for the inspection, and obtain the state's permission. The requirement for advanced notification and consultation severely weakens the IAEA's ability to deter or detect the construction and operation of clandestine facilities.

Special inspections can be compared to the "challenge" inspections provided for in the 1993 Chemical Weapons Convention (CWC). Any CWC party can request a challenge inspection of any location or facility within the territory of any other party. The state being challenged has no legal right to refuse the inspection; under the terms of the Convention, it must provide prompt access to the site in question. ${ }^{28}$ Access to the site can be "managed" by the challenged party, however, to protect proprietary or national-security information; papers can be removed, equipment shrouded, or access can be restricted to randomly selected rooms. This level of access should be more than sufficient to verify compliance with a nuclear disarmament agreement, since ultra-sensitive environmental sampling techniques could detect the distinctive isotopic or chemical signatures of nuclear facilities even if attempts had been made to clean facilities, trap emissions, or move equipment.

\footnotetext{
${ }^{26}$ Producing 1 kilogram of HEU (90-percent U-235) requires 180 to 420 kilograms of natural uranium feed, depending on the tails assay (0.2- to 0.5 -percent U-235), or 4.4 to 10.6 tons of uranium per significant quantity of HEU (25 kilograms). Producing 1 kilogram of weapon-grade plutonium (6-percent Pu-240) requires about 1000 kilograms of natural uranium, assuming a burnup of $1.2 \mathrm{GWd} / \mathrm{te}(\mathrm{U})$ and $0.9 \mathrm{~kg}(\mathrm{Pu}) / \mathrm{GWd}$ for a reactor fueled with natural uranium and moderated with graphite or heavy water, or 8 tons of uranium per significant quantity of plutonium (8 kilograms). Yellowcake $\left(\mathrm{U}_{3} \mathrm{O}_{8}\right)$ is 85 percent uranium.

${ }^{27}$ Current world production of yellowcake is about 90,000 tons per year. The United States, Russia, China, and France each produce about 2,000 tons per year. Only two countries (Canada and Australia) produce substantially more than this; most countries produce much less. A mining and milling operation that yielded 25 to 50 tons per year would represent at least one percent, and often more than 10 percent, of a country's total production.

${ }^{28}$ Requests can be rejected by the CWC Executive Council, however, if they are deemed frivolous, abusive, or beyond the scope of the Treaty.
} 
The preceding discussion has focused on the possibility of detecting undeclared facilities for the production of plutonium or HEU. Some have criticized the IAEA's exclusive focus on safeguarding nuclear materials, reasoning that the NPT's prohibition on the "manufacture" of nuclear explosives applies to the entire research, development, and production process. ${ }^{29}$ Although monitoring authorities certainly should be alert for other signs of weapon development, they should not put much hope in the possibility of detecting the research, development, and manufacture of nuclear weapons, simply because these activities are so easily hidden from spy satellites and on-site inspectors. The United States, with its massive intelligence-gathering apparatus, was unable to identify specific sites of such activities in Iraq, South Africa, or North Korea, but it had much more success in identifying fissile-material production. Weapon-development activities probably would be revealed only through sloppiness or leaks of information. High-explosive assemblies might be tested in distinctive facilities, for example, or a disaffected employee might reveal the location of key facilities. Such discoveries likely would be serendipitous, however, and it is difficult to outline a systematic program for ferreting out such information, aside from general intelligence collection.

One possibility would be to expand the scope of safeguards to materials other than plutonium and HEU that are uniquely useful in nuclear weapons, such as tritium and enriched lithium. In the absence of nuclear weapons, tritium and enriched lithium would be used mostly in nuclear fusion and other scientific research, and therefore might be subjected to safeguards without too much trouble. Other important materials (e.g., beryllium and high explosives) and subcomponents (e.g., neutron generators and high-speed switches) are used in such a wide variety of industrial applications that safeguards of the type now applied to nuclear materials would be impractical and ineffective. Export controls are applied to such items by the Nuclear Suppliers Group, but these controls have been circumvented many times in the past. Export controls could be strengthened as part of a disarmament agreement, but this mechanism has inherent weaknesses that limit its reliability.

Although the existing verification regime appears to have been highly successful in deterring the diversion of significant amounts of materials from safeguarded facilities, it is important to improve the effectiveness and efficiency of safeguards as the number and size of nuclear facilities grow. Of particular concern are facilities that handle large quantities of weapon-usable material in bulk form: reprocessing, enrichment, and mixed-oxide fuel-fabrication facilities. As the size of these facilities

\footnotetext{
${ }^{29}$ Leonard S. Spector, “Repentant Nuclear Proliferators," Foreign Policy, No. 88 (Fall 1992), p. 30-31.
} 
grows and as older facilities in the nuclear-weapon states are placed under safeguards, measurement errors could grow so large that detecting significant diversions of material might be problematic with current techniques. In addition, the current standard for "significant quantity" would have to be revised downward as the current nuclear-weapon states came under safeguards, since these countries know how to build nuclear weapons with far less than the 8 kilograms of plutonium or 25 kilograms of HEU that the IAEA judges necessary for a state to make its first nuclear explosive. ${ }^{30}$ The standard for "timely detection" also would need to be revised from one month to perhaps one week or less, since the current nuclearweapon states presumably could convert diverted material into a fabricated weapon component in a matter of days.

Meeting even the current safeguards standards at large reprocessing plants would strain the limits of safeguards technology, and it may not be possible to meet the more stringent standards suggested here with a reasonable level of monitoring effort. Meeting current standards would require moving to near-real-time accountancy, in which sensors accurately and automatically measure and track the movements of nuclear material within the plant. Facility operators also would have to impose fewer restrictions on the access of inspectors to the plant and demonstrate less concern about the release of proprietary information. Unless inspectors know as much about a plant and its operation as the facility operators themselves, it probably will be impossible to obtain an adequate level of assurance of nondiversion. Indeed, it may simplify safeguards greatly if facility operators simply would share all their data, in real time, with the inspecting agency, which would analyze it for possible inconsistencies or indications of diversion.

Beyond the NPT. The preceding discussion of safeguards has taken place within the constraints of the NPT and the IAEA charter. The NPT does not provide an adequate basis for complete disarmament, however. It is likely that a disarmament agreement would replace the NPT and other existing nuclear arms control treaties. This new agreement would present an opportunity to completely revamp the safeguards regime to include not only the incremental measures noted

\footnotetext{
${ }^{30}$ The amount of material in nuclear weapons is secret, but the U.S. Department of Energy recently stated that "Hypothetically, a mass of 4 kilograms of plutonium...is sufficient for one nuclear explosive device." (Classification Bulletin WNP-86, 8 February 1994; quoted in OTA, Nuclear Safeguards, p. 67.) Nuclear explosives can be built with even less; press reports of the destruction of a Russian nuclear device buried at the Semipalatinsk test site in Kazakhstan stated that the device contained about 1 kilogram of plutonium and would have yielded 1 kiloton.
} 
above, but more far-reaching measures that could alter fundamentally the nature of the nuclear industry and the authority of the IAEA or its successor agency.

A central issue is how nuclear power and other peaceful nuclear activities could be structured and managed in a disarmed world. The first nuclear disarmament proposal, the Baruch Plan, envisioned the creation of an "International Atomic Development Authority" that would manage or own all "potentially dangerous" nuclear activities, inspect and license all other nuclear activities, and be at the forefront of all nuclear research and development. The Authority would control all mining, refining, and distribution of uranium, as well as all facilities capable of producing fissile materials. ${ }^{31}$

An agency with the scope and authority envisioned by the Baruch Plan would be impractical today. When the Baruch Plan was presented by the United States to the United Nations in 1946, nuclear power was a distant dream; today more than 430 nuclear reactors in over 30 countries account for nearly 20 percent of global electricity production. Also, at the time of the Baruch Plan, scientists believed that nuclear fuels could be "denatured" or made unusable for weapons; the denatured fuels would be leased to countries or utilities for use in national facilities. We now know that all nuclear fuel cycles must involve fuels (fresh or spent) that contain weapon-usable materials that can be obtained through a relatively straightforward chemical separation process. Still, it is wise to ask whether aspects of the nuclear fuel cycle that are especially worrisome should be limited or brought under international control as part of a disarmament agreement.

One of the most severe shortcomings of the current regime is that non-nuclearweapon states are permitted to own and operate facilities capable of producing plutonium and HEU in forms that are directly usable in nuclear weapons, and can produce, stockpile, and use these materials so long as they are subject to safeguards. For example, states can enrich uranium, separate plutonium from spent reactor fuel, use plutonium and HEU reactor fuels, and stockpile fresh HEU and separated plutonium. Some of these activities are difficult to safeguard, and all of them pose the risk of rapid break-out from the disarmament regime.

Some analysts believe that the risks associated with civilian uses of HEU and plutonium are so great that commerce in these materials should be discouraged or even outlawed. The United States has been the leading proponent of this view,

\footnotetext{
${ }^{31}$ U.S. Department of State, Documents on Disarmament, 1945-1956 (Washington, DC: U.S. Government Printing Office, 1960), pp. 10-15.
} 
having decided in the late 1970s to discourage the civilian use of HEU and plutonium world-wide. As a result, the United States adopted the "once-through" fuel cycle, in which plutonium-bearing spent fuel is treated as waste, and launched a program to develop LEU fuels for HEU-fueled reactors. The United States reaffirmed its opposition to the use of plutonium fuels in 1993, although it promised not to interfere with the plans of allies with comprehensive nonproliferation commitments and established civilian reprocessing or plutonium facilities.

Few countries share the US view of the dangers of the civilian use of plutonium. Indeed, this policy has been a major point of contention between the United States and three of its closest allies, France, Japan, and the United Kingdom, which have major programs for the separation and use of plutonium. These programs were developed in the 1970s, when demand for nuclear power was projected to grow rapidly and uranium was thought to be relatively scarce. Increased supply and decreased demand has pushed uranium prices to record lows, however, making plutonium uneconomical as a reactor fuel for the foreseeable future. Belgium and Germany have abandoned their domestic reprocessing programs, but several countries, including Russia and India, cling to ambitious plans to expand the use of plutonium fuels in spite of the now obvious economic disadvantages of doing so.

In the long term, plutonium use is tied to the future of nuclear power and uranium extraction. If nuclear power does not expand much beyond the current level, then the price of uranium should remain low and we might avoid building a new generation of reprocessing facilities twenty or thirty years from now. If, on the other hand, the demand for nuclear power grows, then the price of uranium will increase. This might make the use of plutonium fuels economically attractive, triggering a huge expansion in the separation, handling, and transport of plutonium. ${ }^{32}$

If the civilian use of plutonium continued over the longer term, additional technical and institutional barriers could be introduced to increase the probability of detecting diversions, as well as to raise the amount of warning time available. Fissile materials could be placed in forms that would not be directly usable for weapons, or reprocessing and fuel-fabrication processes could be altered so that plutonium would not be present in weapon-usable forms. Schemes that have been suggested include mixing or precipitating uranium with plutonium and adding neutron emitters. These would be significant barriers for subnational groups, but not for most nations

\footnotetext{
${ }^{32}$ Alternatively, it might be cheaper to extract uranium from sea water. Although present at low concentrations, the amount of uranium contained in sea water is huge, and economical extraction would make plutonium use unnecessary.
} 
that host nuclear industries. Adding highly radioactive materials to the fuel, moreover, would add significantly to the costs and hazards of fabricating and handling reactor fuel.

The risks of diversion of weapon-usable materials also could be reduced by internationalizing certain parts of the nuclear fuel cycle. As noted above, traditional IAEA-type safeguards may be unable to detect the diversion of significant quantities of weapon-usable materials in a timely manner from large facilities that handle these materials in bulk form, such as reprocessing, enrichment, and fuel-fabrication plants. If such activities were managed directly by the IAEA or, as envisioned in the Baruch Plan, an "International Atomic Development Authority," it would be easier to deter or detect diversions by states. Similar arrangements could be extended to the storage and use of fresh plutonium and HEU fuels. National reactors might be permitted to burn only LEU fuels, with the spent fuel turned over to international reprocessing or storage centers; reactors burning plutonium or HEU fuels would be managed by an international authority.

Some analysts believe that the continued use of nuclear energy is incompatible with the goal of a disarmed world. As noted above, all fuel cycles involve weaponusable materials; therefore, the use of nuclear energy carries with it the ever-present danger that the host nation would decide to use these materials to build nuclear weapons. The existence of a civilian nuclear industry also maintains technical expertise that could be applied to a weapon program, and provides a background of legal activity against which it would be more difficult to detect an illegal program. Internationalizing certain aspects of the fuel cycle could help deter and detect decisions to go nuclear, but could not prevent civilian nuclear facilities and materials from being redirected to weapons uses. In this view, Article IV of the NPT, in which non-nuclear-weapon states are guaranteed the right "to develop research, production and use of nuclear energy" and "the fullest possible exchange of equipment, materials and scientific and technological information for the peaceful uses of nuclear energy," is fundamentally flawed. 
er is one of the few non-fossil energy sources that can meet a large fraction of global 
3/12/98 DRAFT 
These break-out times set a standard for "timely warning" under a disarmament agreement - the time period in which the international community must be ready to respond to indications of cheating or break-out. As noted above, a response could include economic sanctions designed to cripple an offender's economy, military action designed to destroy the nuclear program or remove the government responsible for initiating it, the readying of conventional forces (or, if they exist, international nuclear forces) to deter or respond to the use of nuclear weapons, or the rebuilding of national nuclear arsenals for the same purpose.

The possibility of rapid break-out could have both positive and negative effects on the prospects for disarmament and the operation of a verification system. On the one hand, the industrialized countries might not worry excessively about the possibility of cheating, because they would be confident in their ability to assemble a nuclear arsenal quickly in an emergency. For this reason, these countries would not be viewed as having strong incentives to violate the agreement clandestinely, and the international community might be satisfied with the reassurance provided by the verification system that such countries were not cheating. On the other hand, countries that intend to violate a disarmament agreement might do so secretly at first, in order to obtain the largest advantage possible, with plans to openly break out if the clandestine program was detected. This possibility could put pressure on the verification system to detect cheating at the earliest possible moment. Dangerous instabilities might result, in which countries, fearing that some other country was cheating and preparing to break out of the agreement, would respond hastily and disproportionately to evidence of cheating - evidence that ultimately might prove to be erroneous. A disarmament regime would have to be structured to avoid such instabilities by allowing the inspection agency time to investigate fully any evidence of cheating without triggering a premature response.

\section{Conclusions}

This paper has outlined the technological possibilities for verifying compliance with a nuclear disarmament treaty. Many of these possibilities do not depend on dramatic improvements in world politics, and could be implemented soon. In particular, it is important for the nuclear-weapon states to declare in detail their stockpiles of nuclear devices and fissile materials and to allow these declarations to be verified. Unless the nuclear weapon states begin this process today, when stockpiles are huge and shrouded in secrecy, they will fail to lay the necessary foundation for nuclear disarmament, because today's uncertainties will be magnified 
greatly as we move from tens of thousands to hundreds of warheads and ultimately to zero.

In the final analysis, however, no conceivable verification regime could provide absolute assurance that former nuclear-weapon states had not hidden a dozen or even a hundred "bombs in the basement" (or enough plutonium or HEU to build such a stockpile), no matter how cooperative and transparent the parties had agreed to be. In other words, even the most intrusive inspection regime could not detect a small stockpile of carefully hidden bombs or plutonium with high confidence. And although improved and expanded IAEA safeguards, together with internationalization of certain aspects of the civilian nuclear fuel cycle, would give states reasonably high confidence that parties were not clandestinely producing fissile materials for nuclear weapons, any state with a substantial nuclear industry would be technically capable of producing or diverting fissile materials and building nuclear weapons in less than a year, and perhaps in as little as a few months.

We therefore are driven to the conclusion that nuclear disarmament would be possible only in a world in which such scenarios were generally regarded as highly unlikely or unimportant. For example, if relations between all the nuclear powers were as congenial as are today's relations between the United States, the United Kingdom, and France, then we would not worry about the possibility of "bombs in the basement" or rapid break-out. If, moreover, the decision-making processes of these and other key governments were as transparent as those of the U.S. government, then states might judge that the probability of hiding bombs or plutonium from inspectors for many years was negligible. Achieving and maintaining such good relations and transparency probably would require having stable democratic governments in place in Russia and China, which would itself increase the prospects for self-enforcement of international obligations.

It may seem as if verification thus has been reduced to a trivial task: in order for disarmament to be possible, states would have to possess a degree of mutual trust and transparency that would make verification (and disarmament itself) a mere formality. This formulation is too simplistic, however, because the disarmament process is iterative. Parties agree to reductions on the assumption of shared goals; the verification of these reductions builds confidence between the parties in that assumption, making increased transparency and deeper reductions possible. The START negotiations made dramatic progress only after relations between the United States and the Soviet Union improved, but START would not have been signed or ratified without the extensive verification provisions it contained. The 
successful implementation of the INF Treaty a few years earlier also was important in creating the environment that made improved relations and the START treaties possible. Indeed, dramatically improved relations between Russia, China, and the other nuclear-weapon states may be possible only in an environment in which they are engaged in a process of mutual and progressive restraints on their nuclear arsenals, since those arsenals are potent symbols of continuing mistrust.

The cheating scenarios outlined above also would become unlikely or unimportant if adequate precautions had been taken to deal with the possibility of small-scale cheating or rapid break-out. If, for example, the nuclear-weapon states and other great powers had pledged to defend each other against aggressors, or to act together to punish nations that violated the nuclear disarmament agreement, then this would decrease the benefits and increase the costs of cheating substantially (assuming, of course, that such pledges were, and were widely believed to be, genuine). Alternatively, an international or multinational nuclear force might be retained to deter or punish cheaters. Somewhat paradoxically, however, the implementation of such safeguards would require a degree of trust and cooperation that would be possible only if cheating by the cooperating states was considered highly unlikely.

One type of safeguard that might not require such dramatic improvements in international relations would be to allow nuclear-weapon states to maintain a capability to build nuclear weapons. States could, for example, be allowed to maintain a small stockpile of plutonium pits and other bomb components in separate storage areas, under international monitoring. An attempt by any state to retrieve these components would trigger alarms in other countries, leading them to assemble and disperse their nuclear weapons. The knowledge that any attempt to cheat or break out of the disarmament agreement would produce an instant and offsetting response by other states would deter cheating in the first place, because cheating could produce no lasting advantage. Maintaining the capacity to rebuild nuclear weapons also would remove the incentive for states to keep a few "bombs in the basement" as a hedge against the possibility that other states might do the same. It would be necessary to protect the bomb-building capacity of each state against preemptive attack by other states, of course, through a combination of multiple sites, deep burial, or provisions for rapid dispersal.

There are two potential problems with this type of safeguard arrangement, however. First, allowing states to maintain the capability to build nuclear weapons on short notice would make it easier for a state to cheat while at the same time 
making it more difficult to detect cheating. States would argue, for example, that they would need nuclear-weapon design laboratories, testing facilities, and facilities to produce tritium and fabricate weapon components. These activities would be of great value for a clandestine program, and would create a background of legal activity against which it would be more difficult to detect illegal activities. Second, having states poised to resume manufacture and deployment could create dangerous instabilities in which states might rush to rearm during a crisis. The possibility of rearming could lead states to disperse their weapon components to protect them from attack, worsening the crisis. If "rules of the road" could be developed to prevent such instabilities, then this sort of arrangement might be a useful way station on the path to a more complete elimination of nuclear-weapon capabilities.

In summary, it would be wrong to believe that nuclear disarmament would be adequately verifiable only when we had learned how to detect with high confidence every hidden bomb or every kilogram of hidden plutonium, and when we had figured out how to prevent or detect any diversion of nuclear materials from peaceful uses. Available verification techniques, if implemented vigorously in a spirit of cooperation, could verify the absence of large-scale cheating, but they could not rule out the possibility of "bombs in the basement" or rapid break-out. Nuclear disarmament will be possible not when small-scale cheating or break-out is impossible, but rather when nations become convinced that such cheating no longer seems very likely or very important. In the meantime, verification of the reductions process will play an essential role in moving us toward a world with the degree of trust and transparency necessary to make this possible. 